\title{
Evaluation of The Cellular and Humoral Immune Response of Sheep Vaccinated with Inactivated Rift Valley Fever Vaccine Adjuvanted with Montanide Gel 01 ${ }^{\mathrm{TM}}$
}

\author{
Abd El Rahman S.E. ${ }^{1}$, Abul Magd, D. M. ${ }^{2^{*}}$, Atwa, M. H. ${ }^{2}$, Soliman, S. M. ${ }^{3}$ \\ ${ }^{1}$ Department of Virology, Faculty of Veterinary Medecine, Mansoura University, Egypt. \\ ${ }^{2}$ Veterinary Serum and Vaccine Research Institute, Abbasia, Cairo, Egypt. \\ ${ }^{3}$ Faculty of Veterinary Medicine, Cairo University, Egypt. \\ "Corresponding author's email: diana2010mohamed@gmail.com
}

\begin{abstract}
Rift Valley Fever (RVF) is an acute infectious zoonotic arthropod - born viral disease, affecting many species of animals with causing great economic losses in animal wealth. Vaccination of susceptible animals with RVF vaccines are an important factor for controlling the disease. This study was applied to improve the locally produced vaccine by using Montanide Gel $01^{\text {TM }}$ as an adjuvant in comparison with Aluminium Hydroxide inactivated RVF vaccine, through evaluating the humeral, cellular immune response and the duration of immunity in sheep vaccinated with the prepared vaccines. The antibody titre in the group vaccinated with one dose of Montanide Gel $01^{\mathrm{TM}}$ inactivated RVF vaccine reached the protective level at the $7^{\text {th }}$-day post-vaccination and stayed within the protective level till the end of the $11^{\text {th }}$ month, while in the group vaccinated with 2 doses, the antibody titre stayed within the protective level till the end of $13^{\text {th }}$ month in sheep vaccinated with the same vaccine. These results revealed that the best vaccine is $20 \%$ Montanide Gel $01^{\mathrm{TM}}$ inactivated RVF vaccine ( 2 doses) as it gave a higher level of antibody throughout the experiment compared with that of other vaccinated groups. Also, the results of cell-mediated immune response showed that: (i) The cell proliferation expressed by optical density showed early significance in sheep vaccinated by Montanide Gel $01^{\mathrm{TM}}$ inactivated RVF vaccine and a slight elevation in sheep vaccinated by Aluminium Hydroxide inactivated RVF vaccine. (ii) The phagocytic activity expressed by phagocytic percentage and phagocytic index showed early significant in sheep vaccinated with Montanide Gel $01^{\text {TM }}$ inactivated RVF vaccine and a slight elevation in sheep vaccinated by Aluminium hydroxide inactivated RVF vaccine. Also, high levels of IL-6 and IL-12 gene expression were detected in sheep vaccinated with Montanide Gel $01^{\mathrm{TM}}$ inactivated RVF vaccine as shown by RT-PCR. All the previous data showed that the Montanide Gel $01^{\mathrm{TM}}$ was highly immunogenic than Aluminium Hydroxide beside that Montanide Gel $01^{\mathrm{TM}}$ inactivated RVF vaccine induces rapid onset immunological response with a long duration which recommended for emergency vaccination.
\end{abstract}

Keywords: Gene expression, Interleukine (IL), Real-time Polymerase Original Article:

DOI :https://dx.doi.org/10.21608/i vs.2020.21145.1002

Received: 01 November, 2020

Accepted :01 January, 2020

Published January, 2020

This is an open access article under the term of the Creative Commons Attribution 4.0 (CC-BY) International License . To view a copy of this license, visit http://creativecommons.org/licenses/by 14.0/

J. Appl. Vet. Sci., 5(1):22-34. Chain Reaction (RT-PCR), Rift Valley Fever (RVF), sheep.

\section{INTRODUCTION}

Rift Valley Fever (RVF) is a viral disease transmitted by mosquitoes. The disease appears as epizootics in domestic cattle and sheep, producing widespread abortions and deaths in young animals. It is a zoonotic disease and highly infectious in Humans, (Digoutte and Peters, 1989). The disease occurs in climatic conditions combined with rainfall every 5-25 years in nonimmune animal's populations (OIE, 2014). RVF disease is caused by Bunyavirus of the Genus Phlebovirus and transmitted by mosquitoes (OIE, 1989).

The best tool for protecting the animal population and indirectly humane being is vector control and vaccination, (Abdel-Gaffar et al., 1979), using a safe and potent inactivated vaccine. During 
epizootics of RVF, the use of live attenuated Smithburn vaccine is recommended (WHO, 1983) but with limitation to be used in pregnant animals due to fear from teratogenic or aborteogenic effect and ability to be converted into a virulent state (Kathryn et al., 1991). The progress in vaccine production is directed towards the selection of the proper adjuvant that can elaborate high and long-standing immunity.Adjuvants are considered as one of the important factors in vaccine formulations that increase the immune response either humoral and cell-mediated immunity (Dalsgrrd et al., 1990).

Montanide Gel $01^{\mathrm{TM}}$ is generic of Montanide as water-based adjuvant designed recently to improve the efficacy of aqueous type vaccine. It was observed that using of Montanide Gel 01TM as adjuvant gave sufficient early immune response in vaccinated cattle associated with a perfect safety profile whatever the nature of the antigen (Dupuis et al., 2008), and it was reported that the antibodies induced were higher than Aluminium-based vaccines and so it can be used associated with a wide range of antigenic media and recommended to be used as adjuvant for sensitive animal's vaccines (Parker $\boldsymbol{e t}$ al., 2009) and (Deville $\boldsymbol{e t}$ al., 2011).

This work aims to improve and enhance the immunogenicity of the locally produced inactivated RVF vaccine to induce high and long duration of immunity in vaccinated animals using Montanide Gel $01^{\mathrm{TM}}$ as an adjuvant.

\section{MATERIALS AND METHODS}

\section{A.MATERIALS}

\section{Experimental animals}

\section{Sheep}

Twenty-five local breed sheep 3-4-month-old were used for evaluation of their immune response to the prepared vaccines. All of these animals were screened using SNT and ELISA and proved to be free from RVF antibodies. They were housed under strict hygienic measures in insect-proof stables receiving balanced ration and adequate water. Also, these animals were examined and proved to be healthy and free from external and internal parasites.

\section{Adult mice}

Swiss albino weaned mice and specific pathogen-free, 21-30 days old supplied by the breeding unit, Veterinary Serum and Vaccine Research Institute, Abbasia, Cairo, Egypt were used for toxicity test of different concentrations of Montanide Gel $01^{\mathrm{TM}}$, titration of the virus, and evaluation of the immune response of the prepared vaccines.

\section{Tissue Culture Cells}

Baby Hamster Kidney cells (BHK21), were grown and maintained according to Macpherson and stocker (1962), and were used for propagation and titration of RVF virus, vaccine production.

\section{Virus}

The original Rift Valley Fever (RVF) virus was isolated from a human patient in Zigzag, Sharkia Province, Egypt and supplied by NUMRU -3. It was designated as ZH501 with a titer of $10^{7.5} \mathrm{TCID}_{50} / \mathrm{ml}$.

\section{Samples \\ Blood samples}

Serum samples were collected from sheep before and after vaccination with the prepared vaccines. Sera were stored at $-20^{\circ} \mathrm{C}$ and inactivated at $56^{\circ} \mathrm{C}$ for 30 minutes before being used in the serological studies (SNT and ELISA).

\section{Heparinized blood samples}

Jugular blood samples from vaccinated and non-vaccinated sheep were collected with anticoagulant (heparin 20-40 IU/ ml) for evaluation of cell-mediated immune response by lymphocyte blastogenesis assay, phagocytic activity test and measuring of interleukin 6 and 12 .

\section{Reagents, kits and media}

\subsection{Adjuvants:}

Aluminium hydroxide gel: The gel was obtained from (Alliance Bio Company, USA), Lot. No. 11-274-30 was used in a concentration of $20 \%$ for local vaccine preparation.

Montanide Gel 01 ${ }^{\mathrm{TM}}$ : Montanide Gel $01^{\mathrm{TM}}$ is based on synthetic polymer classified in the category of high molecular weight polyacrylic acid. It is a white, opaque and flowable gel. Its characteristic viscosity and its ability to work under all $\mathrm{pH}$ conditions make it very easy to handle. It is available in preserved or sterile autoclaved grades. It elicits humoral and cell-mediated immune response without mortality, toxicity or pyrogenic effect, simple to formulate, produced stable emulsion with stability at least 1 year at $4^{\circ} \mathrm{C}$. It was obtained from Seppic, Paris, France.

5.2. RVF antigen: RVF cell lysate antigen was used for IgG antibody detection using ELISA technique. It was Kindly Supplied by RVF department, veterinary serum and vaccine research institute (VSVRI), Abbasia, Cairo.

5.3. Positive control serum: Positive RVF serum was kindly obtained from RVF department Serum and Vaccine Research Institute, Abbasia, Cairo. 
5.4. Negative control serum: Serum from susceptible sheep tested and proved to be free from antibodies against RVF virus.

5.5. ELISA kits: Cat. No. 3340 , was obtained from COSTER 205 Broadway Cambridge, MA 02139.

5.6.Candida albicans: It was kindly supplied by the department of microbiology. The central lab for quality control veterinary biological products, it was used in macrophage activity test.

5.7.Fycoll-hypaque: (Lymphocyte separation medium), used for the separation of mononuclear leukocyte cells from peripheral blood.

5.8. Roswer Park Memorial Institute (RPMI-1640) Medium: RPMI-1640 tissue culture medium with Lglutamine, sodium bicarbonate and antibiotics, was obtained from Flow Lab, UK. Medium sterilization by filtration through a Millipore filter $(0.22 \mu \mathrm{m}$, Sartorius, Germany) followed by storage at $4{ }^{\circ} \mathrm{C}$ until used in lymphocyte blastogenesis assay and phagocytic activity test.

5.9. Methyl alcohol: It is Methanol free from acetone (99.7\%). Country of origin is Germany, from Sigma Company. It was used as $0.3 \mathrm{~cm} /$ well for macrophage activity test.

5.10. Giemsa stain: It was used for phagocyte staining blood sample.

5.11.Fetal bovine serum: supplied by GIBCO, limited, U.K. used for separation of blood lymphocytes.

5.12.Cell proliferation kit (Mdbiosciences-USA): The kit was used in the lymphocyte blastogenesis assay Cat \#: 409005.

5.13.Regents for total RNA extraction from mice lymphocytes using

Trizol:

- Trizol reagent (Invitrogen, Carlsbad, CA).

- Phenol crystals.

- Tris base.

- Distilled water.

- Concentrated HCL to adjust PH of Tris HCL.

- Chloroform.

- Isopropyl alcohol.

- 75\% ethanol in RNA free water.

- RNA free water.

5.14. Reagents and kits for 1st strand cDNA synthesis:

- Anchored oligo (dT) 18 primer.

- Transcriptor 1st strand cDNA synthesis kit (Roche,) using Access
Quick RT-PCR (Promega, USA)Cat. No. A1702 of 100 reactions.

5.15. Reagents and kits for Syber green quantitative real-time PCR:

Primers:

IL 6gene Primers According to Ebrahim et al., (1995)

IL12gene primers according to Sangeeta et al., (2006)

\begin{tabular}{|l|l|l|}
\hline Cytokine & Primer sequence & SIZE \\
\hline IL 6 F. & 5'-ACTTCATCCGAATAGCTCTC-3` & 624 bp \\
\hline IL 6 R. & 5`-ATGAACTCCCTCTTCACAAAG-3` & \\
\hline IL12 F. & 5'-TCTCGGCAGGTGGAAGTCA-3` & \multirow{2}{*}{144 bp } \\
\hline IL12 R. & 5`-ACTTTGGCTGAGGTTTGGTCTG-3` & \\
\hline
\end{tabular}

\section{SYBER Green qPCR kit}

Maxima $^{\mathrm{TM}}$ SYBR Green qPCR Master Mix

(2X) and ROX Solution (fermentas,) cat no. \#K0259

for 60 reactions of $25 \mu 1$.

Kit contents

1- 2XMaxima ${ }^{\mathrm{TM}}$ SYBR Green qPCR Master Mix and a ready-to-use solution containing:(Maxima ${ }^{\mathrm{TM}}$ Hot StartTaq DNA Polymerase, SYBR® Green dye I and dNTPs in an optimized PCR buffer).

2- ROX solution as a passive reference dye

3- RNase-Free Water

Real-time PCR machine: Stratagen MX3005P machine (Stratagen USA).

\section{METHODS}

1.Toxicity test of different concentrations of Montanide Gel 01TM Adjuvantin adult mice

Different concentrations of Montanide Gel $01^{\mathrm{TM}}$ adjuvant in media were prepared $(10 \%, 15 \%, 20$ and $25 \%$ ), for each concentration 10 mice were inoculated (I/P $0.2 \mathrm{ml} / \mathrm{mice}$ ) and kept under daily observation for 10 days post-inoculation (OIE 2012).

\section{Adsorption test}

To detect the most suitable concentration of the adjuvant that can adsorb the efficient amount of antigen by adding each concentration of Montanide Gel $01^{\mathrm{TM}}$ to known virus titre $10^{7} \mathrm{TCID}_{50} / 0.1 \mathrm{ml}$ and then centrifuge the mixture at $1500 \mathrm{rpm}$ for 15 minutes, then titrate the virus remained in the supernatant fluid.

3.Inactivation process: using $\mathrm{BEI}$ according to Blackburn and Besselaar (1991).

\section{Checking the inactivation process}

Samples from the inactivated virus were checked for the presence of active virus as follows:

Safety in Tissue culture: according to OIE (2012).

Safty in baby mice: according to El Nimr (1980) and Eman (1995).

\section{Preparation of RVF vaccine batches}

Preparation of 2 batches of inactivated RVF vaccine as follow: 
Batch 1: using Aluminium hydroxide gel $20 \%$ concentration as an adjuvant.

Batch 2: using Mmontanide gel 20\% concentration as an adjuvant.

\section{Evaluation of the prepared vaccine batches}

6.1. Sterility test: The prepared vaccines were tested for their freedom from Mycoplasma, aerobic, and anaerobic bacteria, fungi.

6.2. Potency test: Fivefold dilutions of each vaccine were prepared in suitable media starting from 1:1 to 1:625. Five groups of adult mice. (21-28 days old) were used for each dilution and each mouse was inoculated with two doses $0.2 \mathrm{ml}$ of the vaccine $\mathrm{I} / \mathrm{P}$, one week apart. Seven days after the second inoculation, all animals were challenged via $\mathrm{I} / \mathrm{P}$ route with $0.1 \mathrm{ml}$ of RVF virus containing $10^{4} \mathrm{MIPD}_{50} / \mathrm{ml}$. In addition to the other two groups of mice, one group was inoculated with challenge virus as positive control and the other group was kept as a non-vaccinated nonchallenged negative control (OIE, 2012).

All groups of mice were kept under observation for 21 days and deaths were recorded daily. The $\mathrm{ED}_{50} / \mathrm{ml}$ was calculated according to the method of Reed and Muench, (1938). Deaths occurring during the first day were considered nonspecific.

\section{Sheep vaccination}

Twenty five sheep of $3-4$ months old were kept in an isolated place and were divided into 5 groups (5 animals/group) as follows:-

Group 1: Each animal vaccinated $(\mathrm{S} / \mathrm{C})$ with $1 \mathrm{ml}$ of inactivated aluminium hydroxide gel adjuvanted RVF vaccine as one dose.

Group 2: Each animal vaccinated (S/C) with $1 \mathrm{ml}$ of inactivated aluminium hydroxide gel adjuvanted RVF vaccine in two doses

Group 3: Each animal vaccinated $(\mathrm{S} / \mathrm{C})$ with $1 \mathrm{ml}$ of inactivated $20 \%$ Montanide Gel $01^{\mathrm{TM}}$ adjuvanted RVF vaccine as one dose.

Group 4: Each animal vaccinated $(\mathrm{S} / \mathrm{C})$ with $1 \mathrm{ml}$ of inactivated 20\% Montanide Gel $01^{\mathrm{TM}}$ adjuvanted RVF vaccine in two doses.

Group 5: kept as non-vaccinated (control negative).

\section{Collection of Samples}

- For evaluation of the humoral immune response: Sera samples were collected from all sheep before and after vaccination at intervals of 7 , 14, 28 days and then monthly for 12 months. (Samples were collected in sterile dry clean screwcapped bottles, then left at room temperature for 12 hours or incubated for 30 minutes then placed in refrigerator overnight, then serum was removed by using sterile pasture pipette and centrifuged at 3000 rpm for 10 minutes), then kept at $-20^{\circ} \mathrm{C}$ until used for antibody detection.
- For cell-mediated immune response: blood samples collected on heparin with intervals of $1,3,5,7,10$ and 15 days post-vaccination.

\section{Evaluation of the humoral immune response}

9.1. Serum Neutralization Test (SNT): This test was used to detect the specific neutralizing antibodies against RVFV in the serum samples of vaccinated sheep according to the method of constant serum- virus dilution procedure. The serum-neutralizing index was calculated according to Reed and Muench, (1938).

9.2. Indirect Enzyme-Linked Immunosorbent Assay (ELISA): According to (Voller et al., 1976), indirect method of ELISA. The cut off value is calculated according to Eduard, (1985).

Cut off = mean optical density of negative control samples +3 (SD of mean negative control samples).

\section{Evaluation of cell-mediated immune response}

10.1. Evaluation of cell-mediated immune response by lymphocyte blastogenesis using XTT assay:

The cleavage of the tetrazolium salt $(3-[4,5-$ dimethyl thiazole-2yl]-2,5 -diphenyl tetrazolium bromide) into a blue coloured product (formazan) by the mitochondrial enzyme succinate dehydrogenase (Slater et al., 1963) is very useful for assaying the cell survival and proliferation. This conversion takes place in the living cells and the amount of formazan produced is proportional to the number of cells present.

The assay was performed as follow:

i) Separation of lymphocytes: Separation of lymphocytes was applied according to Lucy, (1977) and Lee, (1984).

ii) Setting up of lymphocyte and using cell proliferation kit (XTT kit): The test was conducted according to Scudiero et al., (1988).

10.2. Evaluation of the phagocytic activity of macrophages by using Candida Albicans:

i) Separation and cultivation of mononuclear cells: According to Aronthey and Hazen (1988).

ii) Evaluation of phagocytic activity:

Phagocytic \%: It was performed by the method of Harmon and Glisson, (1989), which was modified by Hussein, (1989)

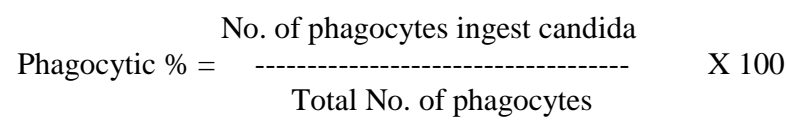

Phagocytic index: It was done according to Richardson and Smith, (1981):

Total No. of phagocytes ingest more than 2 candida

Phagocytic index =

Total No. of phagocytes ingest candida

10.3. (IL6 and IL12) gene analysis by SYBER Green quantitative real time PCR (qPCR) for sheep:

10.3.1.Separation of sheep blood lymphocytes according to Lucy, (1977) and Lee, (1984). 
10.3.2. Total RNA extraction from sheep lymphocytes using Trizol reagent (Invitrogen, Carlsbad, CA): This solution was stored at room temperature and was diluted 1:10 with distilled water before use and $\mathrm{pH}$ were adjusted.

10.3.3. 1st strand cDNA synthesis: Reaction mix volumes/ one reaction using 1st strand cDNA synthesis by Access quick RT-PCR.

\begin{tabular}{|l|c|}
\hline Component & Amount \\
\hline Access quick ${ }^{\mathrm{TM}}$ master mix, 2x & $15 \mu \mathrm{l}$ \\
\hline Uni 12 primer & $10 \mu \mathrm{l}$ \\
\hline Nuclease free water & $0.4 \mu \mathrm{l}$ \\
\hline AMV reverse transcriptase (RT-enzyme) & $0.6 \mu \mathrm{l}$ \\
\hline RNA template & $4 \mu \mathrm{l}$ \\
\hline Final volume & $30 \mu \mathrm{l}$ \\
\hline
\end{tabular}

\section{Thermal profile:}

\begin{tabular}{|l|l|}
\hline Steps & Temperature/Time \\
\hline Reverse transcription & $45^{\circ} \mathrm{C} / 45$ minutes \\
\hline $\begin{array}{l}\text { AMV RT inactivation and } \\
\text { RNA/cDNA/primer } \\
\text { denaturati }\end{array}$ & $92^{\circ} \mathrm{C} / 5$ minutes \\
\hline Hold (refrigeration) & $4^{\circ} \mathrm{C} / \infty$ \\
\hline
\end{tabular}

10.3.4. Syber green real-time PCR For quantification of IL 6 and IL12 in lymphocytes

\begin{tabular}{|l|c|}
\hline Reaction component & Volume/reaction \\
\hline $\begin{array}{l}\text { Maxima } \\
\text { master mix }(2 \mathrm{X})\end{array}$ & $12.5 \mu \mathrm{l}$ \\
\hline Forward primer & $1 \mu \mathrm{l}(10 \mathrm{pmol})$ \\
\hline Reverse primer & $1 \mu \mathrm{l}(10 \mathrm{pmol})$ \\
\hline Template DNA & $(500 \mathrm{ng})$ \\
\hline Nuclease free water & To $25 \mu \mathrm{l}$ \\
\hline
\end{tabular}

The volume of cDNA added from the RT reaction should not exceed $10 \%$ of the final PCR volume.

Thermal profile:

\begin{tabular}{|l|l|}
\hline Step & Temp./time \\
\hline Initial denaturation. & $95^{\circ} \mathrm{C} / 3 \mathrm{~min}$ \\
\hline Denaturation & $95^{\circ} \mathrm{C} / 30 \mathrm{sec}$. \\
\hline Annealing & $55^{\circ} \mathrm{C} / 1 \mathrm{~min}$. \\
\hline Extention & $72^{\circ} \mathrm{C} / 1 \mathrm{~min}$ \\
\hline No. of cycles $(40)$ cycles \\
\hline Dissociation curve & $95^{\circ} \mathrm{C} / 1 \mathrm{~min}$. \\
& $55^{\circ} \mathrm{C} / 30 \mathrm{sec}$. \\
& $95^{\circ} \mathrm{C} / 30 \mathrm{sec}$. \\
\hline
\end{tabular}

\section{Statistical analysis:}

The obtained data were statistically analysed by (SPSS system, version 16) to estimate mean \pm standard error (ST) and ANOVA for the effects of treatment and time on parameters under investigation (SPSS, 2007).

\section{RESULTS}

\section{Toxicity test for different concentrations of Montanide Gel 01 ${ }^{\mathrm{TM}}$ Adjuvant:}

All examined concentrations of Montanide Gel 01TM have no toxic effect and causing no deaths in inoculated mice as shown in table (1).

Table 1: Toxicity test of Montanide Gel $01^{\mathrm{TM}}$ in adult mice:

\begin{tabular}{|c|c|c|c|}
\hline $\begin{array}{c}\text { Concentration in } \\
\text { media }\end{array}$ & No. of mice & Dead & Alive \\
\hline Undiluted & 10 & 0 & 10 \\
\hline $10 \%$ & 10 & 0 & 10 \\
\hline $15 \%$ & 10 & 0 & 10 \\
\hline $20 \%$ & 10 & 0 & 10 \\
\hline $25 \%$ & 10 & 0 & 10 \\
\hline
\end{tabular}

2.Adsorbtion test for selecting the suitable concentration of the adjuvant in tissue culture:

Table (2) showed that the first concentration of Montanide Gel $01^{\mathrm{TM}}$ that showed no cytopathic effect in tissue culture was $20 \%$ so we used this concentration in the prepared vaccine and no virus detected after titration.

Table 2: Titre of the virus in the supernatant fluid of the mixture of the different concentration of Montanide Gel $01^{\mathrm{TM}}$ and the Antigen:

\begin{tabular}{|c|c|c|c|c|}
\hline 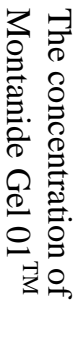 & 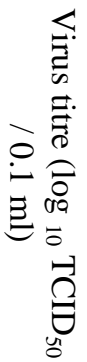 & 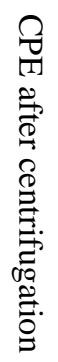 & 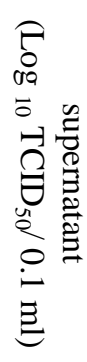 & 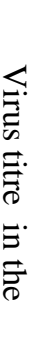 \\
\hline $10 \%$ & $10^{7}$ & ++ & $10^{5}$ & \\
\hline $15 \%$ & $10^{7}$ & + & $10^{3}$ & \\
\hline $20 \%$ & $10^{7}$ & - & - & \\
\hline $25 \%$ & $10^{7}$ & - & - & \\
\hline
\end{tabular}

\section{3- Quality control of the prepared vaccine:}

3.1. Sterility test: revealed that all vaccine preparations are free from any bacterial, fungal or mycoplasmal growth during the period of observation (14 days). 


\subsection{Potency test in mice:}

Both Aluminium hydroxide gel and Montanide Gel 01TM inactivated RVF vaccines gave an acceptable $\mathrm{ED}_{50} / \mathrm{ML}$ (permissible limit $0.02 / \mathrm{ml}$ ) as shown in table (3).

Table 3: $\mathrm{ED}_{50} / \mathrm{ml}$ for the prepared inactivated RVF vaccines in mice (Permissible limit $0.02 / \mathrm{ml}$ ):

\begin{tabular}{|c|c|}
\hline Type of vaccine & $\mathrm{ED}_{50} \backslash \mathrm{ml}$ \\
\hline Aluminium hydroxide gel inactivated RVF vaccine & 0.0017 \\
\hline Montanide Gel 01TM inactivated RVF vaccine 20\% & 0.0011 \\
\hline
\end{tabular}

4.Clinical examination of vaccinated sheep:

This including body temperature for 7 days post-vaccination, there were no clinical signs in all vaccinated groups, no post-vaccinal reaction at the site of injection and no elevation of body temperature

\section{Evaluation of the humoral immune response in sheep vaccinated with different kinds of inactivated RVF vaccines}

\subsection{Results of serum neutralization test (SNT):}

Table 4: Mean of neutralizing indices of sheep vaccinated with aluminium hydroxide and Montanide Gel $01^{\mathrm{TM}}$ inactivated RVF vaccine:

\begin{tabular}{|c|c|c|c|c|c|c|c|c|c|c|c|c|c|c|c|c|c|c|}
\hline \multirow[b]{2}{*}{ 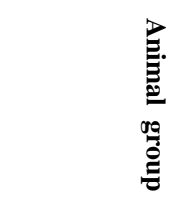 } & \multicolumn{18}{|c|}{ Mean neutralizing indices at different period post vaccination } \\
\hline & $\stackrel{\ominus}{\stackrel{2}{*}}$ & 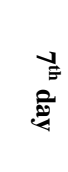 & 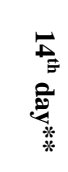 & $\stackrel{\infty}{\stackrel{\infty}{*}}$ & 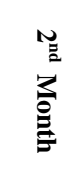 & 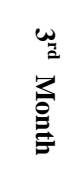 & $\begin{array}{l}\stackrel{A}{E} \\
3 \\
\stackrel{2}{E}\end{array}$ & $\stackrel{\text { Un }}{\text { 光 }}$ & 主 & 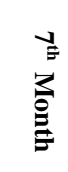 & 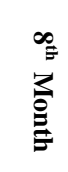 & 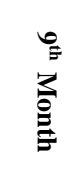 & 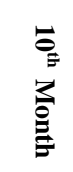 & $\begin{array}{l}\text { 三 } \\
\text { a } \\
\stackrel{\Xi}{E}\end{array}$ & 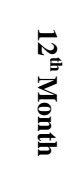 & 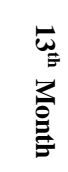 & $\stackrel{\vec{E}}{\stackrel{\vec{E}}{E}}$ & 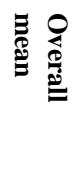 \\
\hline $\begin{array}{c}\text { Gp (1) } \\
\text { vaccinated } \\
\text { with } \\
\text { Aluminium } \\
\text { hydroxide gel } \\
\text { Inactivated } \\
\text { RVF vaccine } \\
\text { (one dose) } \\
\end{array}$ & $\begin{array}{c}0.30 \\
\pm \\
0.01\end{array}$ & $\begin{array}{c}0.90 \\
\pm \\
0.09\end{array}$ & $\begin{array}{c}1.74 \\
\pm \\
0.11\end{array}$ & $\begin{array}{c}2.46 \\
\pm \\
0.15\end{array}$ & $\begin{array}{c}3.00 \\
\pm \\
0.08\end{array}$ & $\begin{array}{c}2.88 \\
\pm \\
0.09\end{array}$ & $\begin{array}{c}2.63 \\
\pm \\
0.07\end{array}$ & $\begin{array}{c}2.52 \\
\pm \\
0.12\end{array}$ & $\begin{array}{c}2.16 \\
\pm \\
0.11\end{array}$ & $\begin{array}{c}1.92 \\
\pm \\
0.07\end{array}$ & $\begin{array}{c}1.54 \\
\pm \\
0.11\end{array}$ & $\begin{array}{c}1.32 \\
\pm \\
0.06\end{array}$ & $\begin{array}{c}0.96 \\
\pm \\
0.06\end{array}$ & $\begin{array}{c}0.6 \\
\pm \\
0.09\end{array}$ & $\begin{array}{c}0.6 \\
\pm \\
0.09\end{array}$ & $\begin{array}{c}0.6 \\
\pm \\
0.15\end{array}$ & $\begin{array}{c}0.6 \\
\pm \\
0.15\end{array}$ & $\begin{array}{c}1^{d} \\
\pm \\
0.11\end{array}$ \\
\hline $\begin{array}{c}\text { Gp (2) } \\
\text { vaccinated } \\
\text { with } \\
\text { Aluminium } \\
\text { hydroxide gel } \\
\text { Inactivated } \\
\text { RVF vaccine } \\
\text { (two doses) } \\
\end{array}$ & $\begin{array}{c}0.39 \\
\pm \\
0.09\end{array}$ & $\begin{array}{c}0.93 \\
\pm \\
0.15\end{array}$ & $\begin{array}{c}1.7 \\
\pm \\
0.12\end{array}$ & $\begin{array}{c}3.32 \\
\pm \\
0.08\end{array}$ & $\begin{array}{c}3.25 \\
\pm \\
0.09\end{array}$ & $\begin{array}{c}3.17 \\
\pm \\
0.11\end{array}$ & $\begin{array}{c}3.0 \\
\pm \\
0.06\end{array}$ & $\begin{array}{c}2.72 \\
\pm \\
0.12\end{array}$ & $\begin{array}{c}2.66 \\
\pm \\
0.09\end{array}$ & $\begin{array}{c}2.50 \\
\pm \\
0.15\end{array}$ & $\begin{array}{c}2.09 \\
\pm \\
0.09\end{array}$ & $\begin{array}{c}1.91 \\
\pm \\
0.06\end{array}$ & $\begin{array}{c}1.75 \\
\pm \\
0.09\end{array}$ & $\begin{array}{c}1.15 \\
\pm \\
0.15\end{array}$ & $\begin{array}{c}0.76 \\
\pm \\
0.12\end{array}$ & $\begin{array}{c}0.6 \\
\pm \\
0.15\end{array}$ & $\begin{array}{c}0.6 \\
\pm \\
0.09\end{array}$ & $\begin{array}{c}1.8 \\
\pm \\
\pm \\
0.08\end{array}$ \\
\hline $\begin{array}{c}\text { Gp (3) } \\
\text { vaccinated } \\
\text { with } \\
\text { Montanide } \\
\text { Gel 01TM } \\
\text { inactivated } \\
\text { RVF vaccine } \\
20 \% \text { (one } \\
\text { dose) } \\
\end{array}$ & $\begin{array}{c}0.42 \\
\pm \\
0.09\end{array}$ & $\begin{array}{c}2.04 \\
\pm \\
0.15\end{array}$ & $\begin{array}{c}2.52 \\
\pm \\
0.06\end{array}$ & $\begin{array}{c}2.82 \\
\pm \\
0.12\end{array}$ & $\begin{array}{c}3.52 \\
\pm \\
0.15\end{array}$ & $\begin{array}{c}3.71 \\
\pm \\
0.09\end{array}$ & $\begin{array}{c}3.64 \\
\pm \\
0.12\end{array}$ & $\begin{array}{c}3.54 \\
\pm \\
0.02\end{array}$ & $\begin{array}{c}3.22 \\
\pm \\
0.15\end{array}$ & $\begin{array}{c}2.82 \\
\pm \\
0.05\end{array}$ & $\begin{array}{c}2.52 \\
\pm 0 \\
.02\end{array}$ & $\begin{array}{c}2.04 \\
\pm \\
0.09\end{array}$ & $\begin{array}{c}1.8 \\
\pm \\
0.15\end{array}$ & $\begin{array}{c}1.70 \\
\pm \\
0.09\end{array}$ & $\begin{array}{c}1.32 \\
\pm \\
0.12\end{array}$ & $\begin{array}{c}0.6 \\
\pm \\
0.09\end{array}$ & $\begin{array}{c}0.6 \\
\pm \\
0.09\end{array}$ & $\begin{array}{c}2.3^{b} \\
\pm \\
0.11\end{array}$ \\
\hline $\begin{array}{c}\text { Gp (4) } \\
\text { vaccinated } \\
\text { with } \\
\text { Montanide } \\
\text { Gel 01TM } \\
\text { inactivated } \\
\text { RVF vaccine } \\
20 \% \text { (two } \\
\text { doses) }\end{array}$ & $\begin{array}{c}0.32 \\
\pm \\
0.09\end{array}$ & $\begin{array}{c}2.07 \\
\pm \\
0.12\end{array}$ & $\begin{array}{c}2.56 \\
\pm \\
0.02\end{array}$ & $\begin{array}{c}3.01 \\
\pm \\
0.11\end{array}$ & $\begin{array}{c}3.99 \\
\pm \\
0.15\end{array}$ & $\begin{array}{c}3.87 \\
\pm \\
0.12\end{array}$ & $\begin{array}{c}3.70 \\
\pm \\
0.09\end{array}$ & $\begin{array}{c}3.59 \\
\pm \\
0.08\end{array}$ & $\begin{array}{c}3.37 \\
\pm \\
0.09\end{array}$ & $\begin{array}{c}3.19 \\
\pm \\
0.12\end{array}$ & $\begin{array}{c}2.87 \\
\pm \\
0.11\end{array}$ & $\begin{array}{c}2.45 \\
\pm \\
0.15\end{array}$ & $\begin{array}{c}2.29 \\
\pm \\
0.08\end{array}$ & $\begin{array}{c}2.11 \\
\pm \\
0.12\end{array}$ & $\begin{array}{c}1.9 \\
\pm \\
0.09\end{array}$ & $\begin{array}{c}1.7 \\
\pm \\
0.15\end{array}$ & $\begin{array}{c}1.4 \\
\pm \\
0.09\end{array}$ & $\begin{array}{c}2.5^{\mathrm{a}} \\
\pm \\
0.11\end{array}$ \\
\hline $\begin{array}{c}\text { Gp (5) } \\
\text { Non- } \\
\text { vaccinated } \\
\text { control } \\
\end{array}$ & $\begin{array}{c}0.6 \\
\pm \\
0.09\end{array}$ & $\begin{array}{c}0.6 \\
\pm \\
0.12\end{array}$ & $\begin{array}{c}0.6 \\
\pm \\
0.08\end{array}$ & $\begin{array}{c}0.6 \\
\pm \\
0.11\end{array}$ & $\begin{array}{c}0.75 \\
\pm \\
0.12\end{array}$ & $\begin{array}{c}0.6 \\
\pm \\
0.15\end{array}$ & $\begin{array}{c}0.6 \\
\pm \\
0.6\end{array}$ & $\begin{array}{c}0.9 \\
\pm \\
0.15\end{array}$ & $\begin{array}{c}0.6 \\
\pm \\
0.15\end{array}$ & $\begin{array}{c}0.6 \\
\pm \\
0.12\end{array}$ & $\begin{array}{c}0.6 \\
\pm \\
0.15\end{array}$ & $\begin{array}{c}0.45 \\
\pm \\
0.09\end{array}$ & $\begin{array}{c}0.6 \\
\pm \\
0.12\end{array}$ & $\begin{array}{c}0.6 \\
\pm \\
0.09\end{array}$ & $\begin{array}{c}0.45 \\
\pm \\
0.15\end{array}$ & $\begin{array}{c}0.6 \\
\pm \\
0.09\end{array}$ & $\begin{array}{c}0.72 \\
\pm \\
0.09\end{array}$ & $\begin{array}{c}0.61 \\
\pm \\
0.02\end{array}$ \\
\hline
\end{tabular}

Values with different alphabetic within the right column showed highly significant difference at $\mathrm{P}<0.01$.

$(* *)$ time of the $2^{\text {nd }}$ dose. Protective level 1.7 . 
Fig.1: Mean of neutralizing indices of sheep vaccinated with Aluminium hydroxide and Montanide Gel $01^{\text {TM }}$ inactivated RVF vaccine:

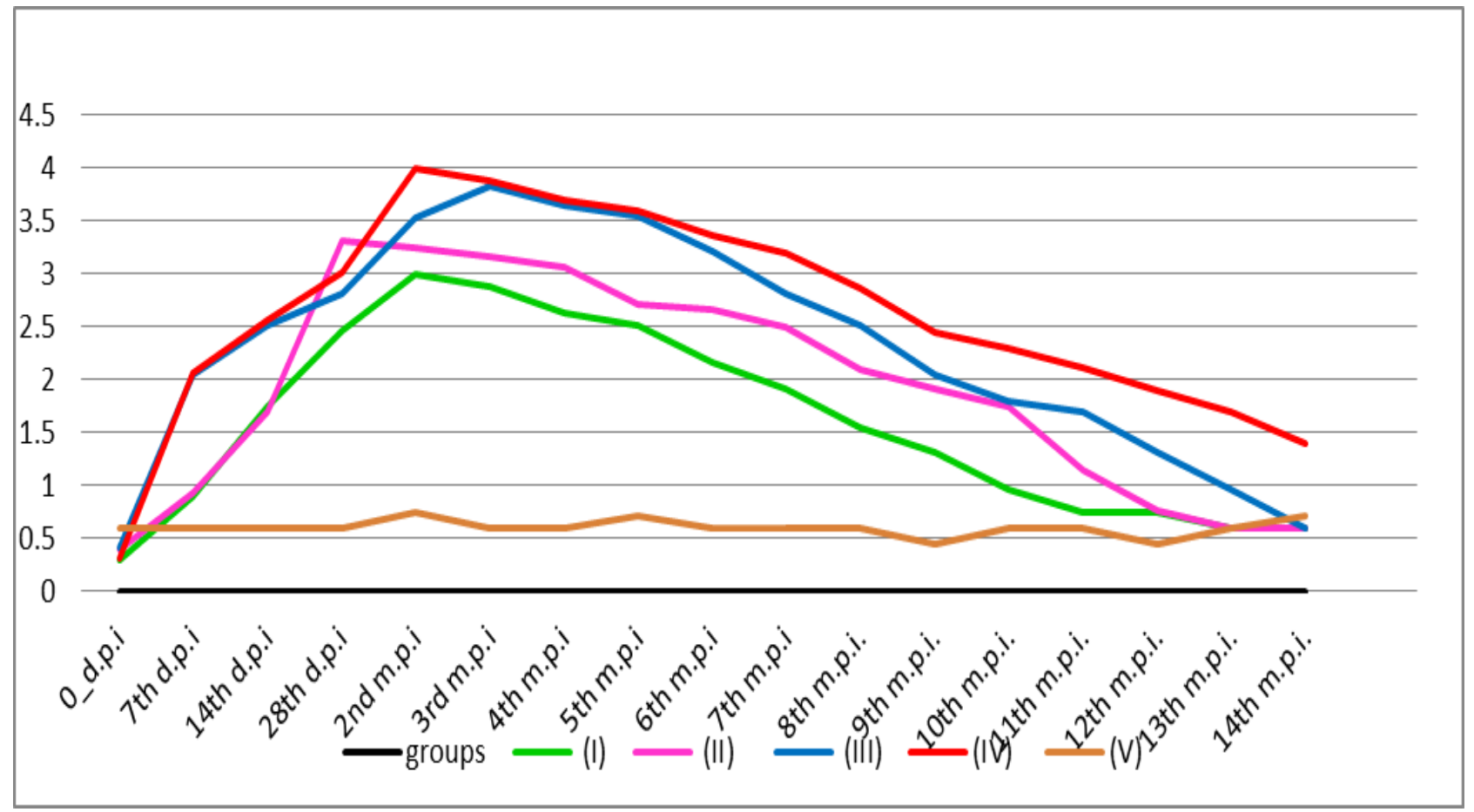

Fig.2: Mean values of ELISA optical density in sheep vaccinated with aluminium hydroxide and Montanide Gel $01^{\mathrm{TM}}$ inactivated RVF vaccine:

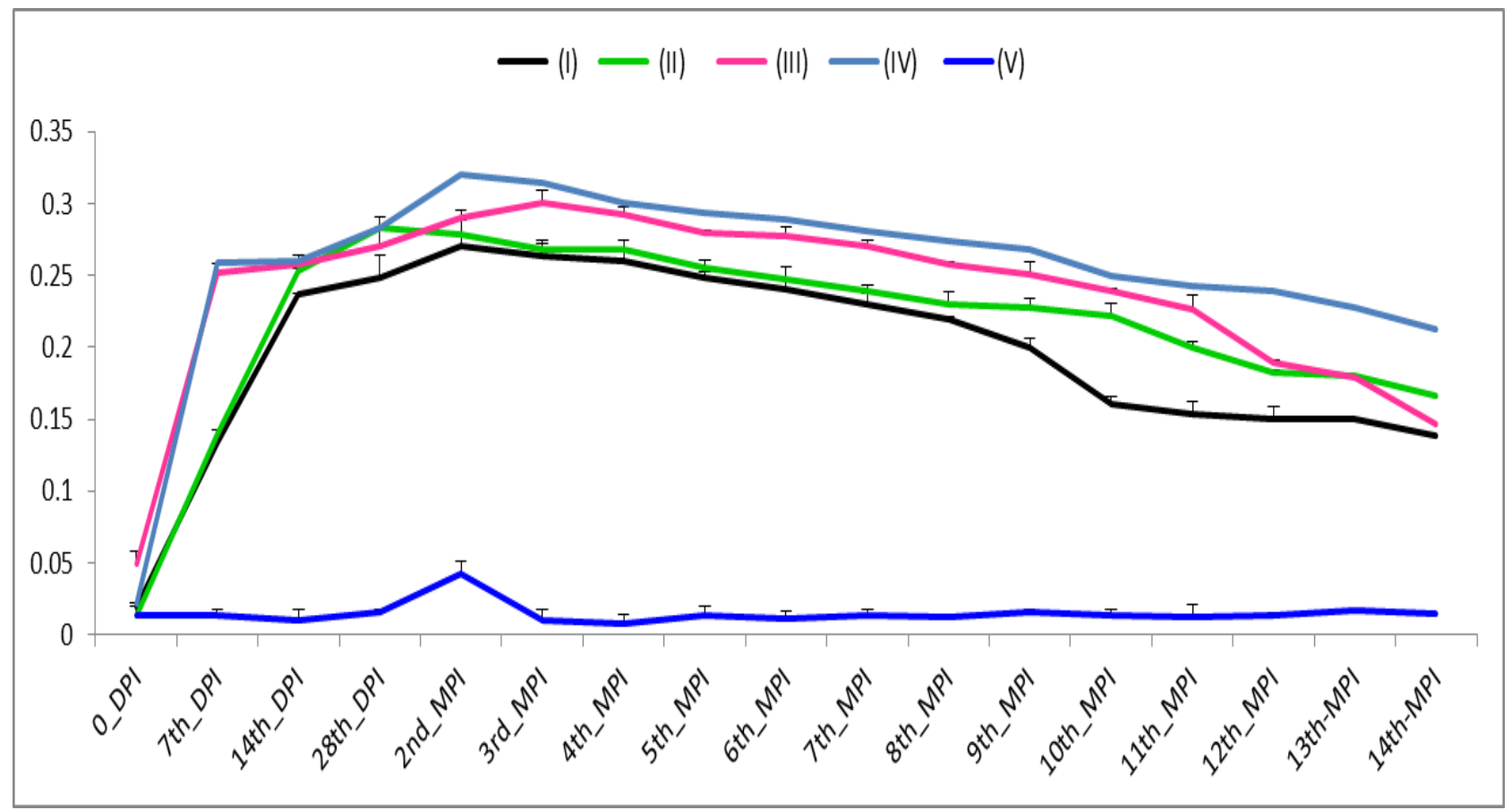




\section{Abd El Rahman S.E. et al......}

\subsection{Results of ELISA}

Table 5: Mean values of ELISA optical density in sheep vaccinated with aluminium hydroxide and Montanide Gel $01^{\mathrm{TM}}$ inactivated $\mathrm{RVF}$ vaccine:

\begin{tabular}{|c|c|c|c|c|c|c|c|c|c|c|c|c|c|c|c|c|c|c|}
\hline \multirow{2}{*}{ 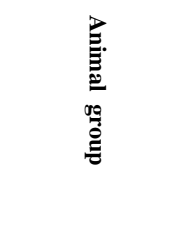 } & \multicolumn{18}{|c|}{ Mean optical densities at different period post-vaccination } \\
\hline & 을 & 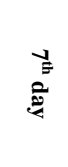 & 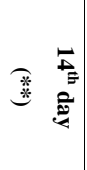 & 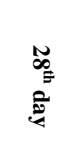 & $\underbrace{\cong}_{3}$ & ${ }_{3}^{w}$ & $\begin{array}{l}\vec{E} \\
3\end{array}$ & $\begin{array}{l}U_{11} \\
\stackrel{3}{\xi}\end{array}$ & $\hat{\xi}$ & $\stackrel{v}{\Xi}$ & $\stackrel{\infty}{3}$ & $\begin{array}{l}0 \\
\vdots \\
3\end{array}$ & $\begin{array}{l}\vec{\theta} \\
\underline{E} \\
\underline{3}\end{array}$ & $\begin{array}{l}\Xi \\
\underline{E} \\
?\end{array}$ & $\begin{array}{l}\text { N } \\
? \\
?\end{array}$ & $\begin{array}{l}\vec{W}_{\Xi} \\
\vdots\end{array}$ & $\begin{array}{l}\stackrel{\vec{E}}{E} \\
3 \\
3\end{array}$ & 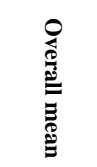 \\
\hline $\begin{array}{c}\text { Gp (1) } \\
\text { vaccinated } \\
\text { with Aluminium } \\
\text { hydroxide gel } \\
\text { Inactivated RVF } \\
\text { vaccine } \\
\text { (one dose) }\end{array}$ & $\begin{array}{c}0.019 \\
\pm \\
0.001\end{array}$ & $\begin{array}{c}0.134 \\
\pm \\
0.009\end{array}$ & $\begin{array}{c}0.237 \\
\pm \\
0.001\end{array}$ & $\begin{array}{c}0.249 \\
\pm \\
0.015\end{array}$ & $\begin{array}{c}0.270 \\
\pm \\
0.008\end{array}$ & $\begin{array}{c}0.263 \\
\pm \\
0.009\end{array}$ & $\begin{array}{c}0.260 \\
\pm \\
0.007\end{array}$ & $\begin{array}{c}0.248 \\
\pm \\
0.004\end{array}$ & $\begin{array}{c}0.240 \\
\pm \\
0.007\end{array}$ & $\begin{array}{c}0.230 \\
\pm \\
0.007\end{array}$ & $\begin{array}{c}0.220 \\
\pm \\
0.001\end{array}$ & $\begin{array}{c}0.200 \\
\pm \\
0.006\end{array}$ & $\begin{array}{c}0.160 \\
\pm \\
0.006\end{array}$ & $\begin{array}{c}0.153 \\
\pm \\
0.009\end{array}$ & $\begin{array}{c}0.150 \\
\pm \\
0.009\end{array}$ & $\begin{array}{c}0.150 \\
\pm \\
0.006\end{array}$ & $\begin{array}{c}0.139 \\
\pm \\
0.006\end{array}$ & $\begin{array}{c}0.188^{\mathrm{d}} \\
\pm \\
0.11\end{array}$ \\
\hline $\begin{array}{c}\text { Gp (2) } \\
\text { vaccinated } \\
\text { with Aluminium } \\
\text { hy } \\
\text { droxide gel } \\
\text { Inactivated } \\
\text { RVF vaccine } \\
\text { (two doses) }\end{array}$ & $\begin{array}{c}0.013 \\
\pm \\
0.009\end{array}$ & $\begin{array}{c}0.140 \\
\pm \\
0.002\end{array}$ & $\begin{array}{c}0253 \\
\pm \\
0.002\end{array}$ & $\begin{array}{c}0.283 \\
\pm \\
0.008\end{array}$ & $\begin{array}{c}0.279 \\
\pm \\
0.009\end{array}$ & $\begin{array}{c}0.268 \\
\pm \\
0.007\end{array}$ & $\begin{array}{c}0.268 \\
\pm \\
0.006\end{array}$ & $\begin{array}{c}0.255 \\
\pm \\
0.006\end{array}$ & $\begin{array}{c}0.247 \\
\pm \\
0.009\end{array}$ & $\begin{array}{c}0.239 \\
\pm \\
0.004\end{array}$ & $\begin{array}{c}0.230 \\
\pm \\
0.009\end{array}$ & $\begin{array}{c}0.228 \\
\pm \\
0.006\end{array}$ & $\begin{array}{c}0.222 \\
\pm \\
0.009\end{array}$ & $\begin{array}{c}0.200 \\
\pm \\
0.004\end{array}$ & $\begin{array}{c}0.183 \\
\pm \\
0.001\end{array}$ & $\begin{array}{c}0.170 \\
\pm \\
0.009\end{array}$ & $\begin{array}{c}0.150 \\
\pm \\
0.001\end{array}$ & $\begin{array}{c}0.192^{\mathrm{c}} \\
\pm \\
0.08\end{array}$ \\
\hline $\begin{array}{c}\text { Gp (3) } \\
\text { vaccinated } \\
\text { with Montanide } \\
\text { Gel 01TM } \\
\text { inactivated } \\
\text { RVF vaccine } \\
20 \% \\
\text { (one dose) }\end{array}$ & $\begin{array}{c}0.049 \\
\pm \\
0.009\end{array}$ & $\begin{array}{c}0.252 \\
\pm \\
0.006\end{array}$ & $\begin{array}{c}0.258 \\
\pm \\
0.006\end{array}$ & $\begin{array}{c}0.271 \\
\pm \\
0.005\end{array}$ & $\begin{array}{c}0.290 \\
\pm \\
0.005\end{array}$ & $\begin{array}{c}0.300 \\
\pm \\
0.009\end{array}$ & $\begin{array}{c}0.292 \\
\pm \\
0.006\end{array}$ & $\begin{array}{c}0.280 \\
\pm \\
0.002\end{array}$ & $\begin{array}{c}0.277 \\
\pm \\
0.007\end{array}$ & $\begin{array}{c}0.270 \\
\pm \\
0.005\end{array}$ & $\begin{array}{c}0.258 \\
\pm \\
0.002\end{array}$ & $\begin{array}{c}0.251 \\
\pm \\
0.009\end{array}$ & $\begin{array}{c}0.239 \\
\pm \\
0.002\end{array}$ & $\begin{array}{c}0.227 \\
\pm \\
0.009\end{array}$ & $\begin{array}{c}0.190 \\
\pm \\
0.001\end{array}$ & $\begin{array}{c}0.179 \\
\pm \\
0.001\end{array}$ & $\begin{array}{c}0.147 \\
\pm \\
0.009\end{array}$ & $\begin{array}{c}0.228^{b} \\
\pm \\
0.11\end{array}$ \\
\hline $\begin{array}{c}\text { Gp (4) } \\
\text { vaccinated } \\
\text { with Montanide } \\
\text { Gel 01TM } \\
\text { inactivated } \\
\text { RVF vaccine 20 } \\
\% \\
\text { (two doses) }\end{array}$ & $\begin{array}{c}0.022 \\
\pm \\
0.009\end{array}$ & $\begin{array}{c}0.259 \\
\pm \\
0.019\end{array}$ & $\begin{array}{c}0.260 \\
\pm \\
0.002\end{array}$ & $\begin{array}{c}0.283 \\
\pm \\
0.001\end{array}$ & $\begin{array}{c}0.320 \\
\pm \\
0.006\end{array}$ & $\begin{array}{c}0.314 \\
\pm \\
0.008\end{array}$ & $\begin{array}{c}0.300 \\
\pm \\
0.009\end{array}$ & $\begin{array}{c}0.294 \\
\pm \\
0.008\end{array}$ & $\begin{array}{c}0.289 \\
\pm \\
0.009\end{array}$ & $\begin{array}{c}0.281 \\
\pm \\
0.009\end{array}$ & $\begin{array}{c}0.274 \\
\pm \\
0.001\end{array}$ & $\begin{array}{c}0.268 \\
\pm \\
0.001\end{array}$ & $\begin{array}{c}0.250 \\
\pm \\
0.001\end{array}$ & $\begin{array}{c}0.243 \\
\pm \\
0.002\end{array}$ & $\begin{array}{c}0.239 \\
\pm \\
0.008\end{array}$ & $\begin{array}{c}0.228 \\
\pm \\
0.009\end{array}$ & $\begin{array}{c}0.213 \\
\pm \\
0.001\end{array}$ & $\begin{array}{c}0.281^{\mathrm{a}} \\
\pm \\
0.11\end{array}$ \\
\hline $\begin{array}{c}\text { Gp }(5) \\
\text { Non-vaccinated } \\
\text { control }\end{array}$ & $\begin{array}{c}0.013 \\
\pm \\
0.009\end{array}$ & $\begin{array}{c}0.013 \\
\pm \\
0.004\end{array}$ & $\begin{array}{c}0.010 \\
\pm \\
0.008\end{array}$ & $\begin{array}{c}0.016 \\
\pm \\
0.001\end{array}$ & $\begin{array}{c}0.043 \\
\pm \\
0.008\end{array}$ & $\begin{array}{c}0.010 \\
\pm \\
0.007\end{array}$ & $\begin{array}{c}0.008 \\
\pm \\
0.006\end{array}$ & $\begin{array}{c}0.013 \\
\pm \\
0.007\end{array}$ & $\begin{array}{c}0.011 \\
\pm \\
0.005\end{array}$ & $\begin{array}{c}0.013 \\
\pm \\
0.004\end{array}$ & $\begin{array}{c}0.012 \\
\pm \\
0.002\end{array}$ & $\begin{array}{c}0.016 \\
\pm \\
0.001\end{array}$ & $\begin{array}{c}0.013 \\
\pm \\
0.005\end{array}$ & $\begin{array}{c}0.012 \\
\pm \\
0.009\end{array}$ & $\begin{array}{c}0.014 \\
\pm \\
0.001\end{array}$ & $\begin{array}{c}\mid 0.017 \\
\pm \\
0.009\end{array}$ & $\begin{array}{c}0.015 \\
\pm \\
0.001\end{array}$ & $\begin{array}{c}0.014^{(e)} \\
\pm \\
0.02\end{array}$ \\
\hline
\end{tabular}


6. Evaluation of the cell-mediated immune response in sheep vaccinated with gel inactivated RVF vaccine: 6.1. Lymphocyte blastogenesis:

It was noticed that, cell proliferation expressed by optical density was early high in Gp.3 but more strong in Gp.4 and a slight elevation in Gp.1 and 2 as shown in table (6).

Table 6: Results of lymphocytic blastogenesis assay obtained in different sheep groups after vaccination with RVF prepared vaccines.

\begin{tabular}{|c|c|c|c|c|c|c|c|c|}
\hline \multirow{3}{*}{ Sheep group } & \multirow{3}{*}{$\begin{array}{l}\text { No. of } \\
\text { sheep }\end{array}$} & \multicolumn{6}{|c|}{ Mean optical densities of proliferation assay } & \multirow{3}{*}{$\begin{array}{c}\text { Overall } \\
\text { mean }\end{array}$} \\
\hline & & \multicolumn{6}{|c|}{ Days post-vaccination } & \\
\hline & & $1^{\text {st }}$ & $3 \mathrm{rd}$ & 5 th & 7 th & 10 th & 15 th & \\
\hline Gp (1) vaccinated with Aluminium & & 0.32 & 0.41 & 0.47 & 0.44 & 0.39 & 0.34 & $0.39^{\mathrm{d}}$ \\
\hline hydroxide gel Inactivated RVF & 5 & \pm & \pm & \pm & \pm & \pm & \pm & \pm \\
\hline vaccine (one dose) & & 0.08 & 0.09 & 0.11 & 0.07 & 0.12 & 0.09 & 0.08 \\
\hline Gp (2) vaccinated with Aluminium & & 0.45 & 0.53 & 0.64 & 0.67 & 0.56 & 0.47 & $0.55^{\mathrm{c}}$ \\
\hline $\begin{array}{l}\text { hydroxide gel Inactivated RVF } \\
\text { vaccine (two doses) }\end{array}$ & 5 & $\stackrel{ \pm}{0.11}$ & $\begin{array}{c} \pm \\
0.09\end{array}$ & $\begin{array}{c} \pm \\
0.09\end{array}$ & $\stackrel{ \pm}{0.08}$ & $\begin{array}{c} \pm \\
0.08\end{array}$ & $\begin{array}{c} \pm \\
0.09\end{array}$ & $\stackrel{ \pm}{0.07}$ \\
\hline Gp (3) vaccinated with & & 0.59 & 0.66 & 0.82 & 0.90 & 0.88 & 0.76 & $0.76^{\mathrm{b}}$ \\
\hline Montanide Gel 01TM inactivated & 5 & \pm & \pm & \pm & \pm & \pm & \pm & \pm \\
\hline RVF vaccine $20 \%$ (one dose) & & 0.08 & 0.07 & 0.07 & 0.08 & 0.09 & 0.11 & 0.08 \\
\hline Gp (4) vaccinated with Montanide Gel & & 0.66 & 0.72 & 0.90 & 1.1 & 1.4 & 0.83 & $0.94^{\mathrm{a}}$ \\
\hline $\begin{array}{l}\text { 01TM inactivated RVF vaccine } 20 \% \\
\text { (two doses) }\end{array}$ & 5 & $\begin{array}{c} \pm \\
0.09\end{array}$ & $\begin{array}{c} \pm \\
0.09\end{array}$ & \pm & $\pm \stackrel{ \pm}{09}$ & \pm 09 & \pm & \pm \\
\hline $\mathrm{Gp}(5)$ & & 0.11 & 0.09 & 0.11 & 0.1 & 0.12 & 0.11 & $0.1^{\mathrm{e}}$ \\
\hline Non-vaccinated control & 5 & $\begin{array}{c} \pm \\
0.09\end{array}$ & $\begin{array}{c} \pm \\
0.08 \\
\end{array}$ & $\begin{array}{c} \pm \\
0.08 \\
\end{array}$ & $\begin{array}{c} \pm \\
0.07\end{array}$ & $\begin{array}{c} \pm \\
0.09\end{array}$ & $\begin{array}{c} \pm \\
0.08\end{array}$ & $\begin{array}{c} \pm \\
0.08\end{array}$ \\
\hline
\end{tabular}

Values with different alphabetic within the right column showed highly significant difference at $\mathrm{P}<0.01$.

\subsection{Phagocytic activity test}

Table 7: Results of phagocytic percentage obtained in different sheep groups after vaccination with RVF prepared vaccines.

\begin{tabular}{|c|c|c|c|c|c|c|c|c|}
\hline \multirow{3}{*}{ Sheep group } & \multirow{3}{*}{$\begin{array}{l}\text { No. of } \\
\text { sheep }\end{array}$} & \multicolumn{6}{|c|}{ Phagocytic percentage (\%) } & \multirow{3}{*}{$\begin{array}{c}\text { Overall } \\
\text { mean }\end{array}$} \\
\hline & & \multicolumn{6}{|c|}{ Days post-vaccination } & \\
\hline & & $1^{\text {st }}$ & $3 \mathrm{rd}$ & 5 th & 7 th & 10 th & 15 th & \\
\hline \multirow{3}{*}{$\begin{array}{l}\text { Gp (1) vaccinated with Aluminium hydroxide } \\
\text { gel Inactivated RVF vaccine (one dose) }\end{array}$} & \multirow{3}{*}{5} & 27 & 32 & 36 & 34 & 31 & 28 & $31.3^{\mathrm{d}}$ \\
\hline & & \pm & \pm & \pm & \pm & \pm & \pm & \pm \\
\hline & & 0.08 & 0.09 & 0.11 & 0.07 & 0.07 & 0.11 & 0.08 \\
\hline \multirow{3}{*}{$\begin{array}{l}\text { Gp (2) vaccinated with Aluminium hydroxide } \\
\text { gel Inactivated RVF vaccine (two doses) }\end{array}$} & \multirow{3}{*}{5} & 44 & 48 & 54 & 56 & 52 & 48 & $50.3^{\mathrm{c}}$ \\
\hline & & \pm & \pm & \pm & \pm & \pm & \pm & \pm \\
\hline & & 0.07 & 0.08 & 0.09 & 0.11 & 0.08 & 0.07 & 0.07 \\
\hline \multirow{3}{*}{$\begin{array}{l}\text { Gp (3) vaccinated with Montanide Gel 01TM } \\
\text { inactivated RVF vaccine } 20 \% \text { (one dose) }\end{array}$} & \multirow{3}{*}{5} & 62 & 65 & 72 & 78 & 74 & 68 & $69^{\mathrm{b}}$ \\
\hline & & \pm & \pm & \pm & \pm & \pm & \pm & \pm \\
\hline & & .08 & 0.07 & 0.07 & 0.07 & 0.08 & 0.08 & 0.09 \\
\hline \multirow{3}{*}{$\begin{array}{l}\text { Gp (4) vaccinated with Montanide Gel 01TM } \\
\text { inactivated RVF vaccine } 20 \% \text { (two doses) }\end{array}$} & \multirow{3}{*}{5} & 66 & 70 & 74 & 79 & 81 & 83 & $75^{(\mathrm{a})}$ \\
\hline & & \pm & \pm & \pm & \pm & \pm & \pm & \pm \\
\hline & & 0.07 & 0.08 & 0.11 & 0.08 & 0.11 & 0.09 & 0.11 \\
\hline \multirow{3}{*}{$\begin{array}{l}\text { Gp (5) } \\
\text { Non-vaccinated control }\end{array}$} & \multirow{3}{*}{5} & 21 & 18 & 19 & 20 & 17 & 19 & $19^{\mathrm{e}}$ \\
\hline & & \pm & \pm & \pm & \pm & \pm & \pm & \pm \\
\hline & & 0.07 & 0.09 & 0.08 & 0.09 & 0.11 & 0.07 & 0.07 \\
\hline
\end{tabular}

Values with different alphabetic within the right column showed highly significant difference at $\mathrm{P}<0.01$. 
Phagocytic activity was expressed by phagocytic percentage and phagocytic index in different groups as shown in table (7) and (8). It was noticed that there was early high macrophage activity in Gp.(3) but more strong in Gp.(4) and nearly slight elevation in Gp.(1) and (2).

Table 8: Results of phagocytic indices obtained in different sheep groups after vaccination with RVF prepared vaccines.

\begin{tabular}{|c|c|c|c|c|c|c|c|c|}
\hline \multirow{3}{*}{ Sheep group } & \multirow{3}{*}{$\begin{array}{l}\text { No. of } \\
\text { sheep }\end{array}$} & \multicolumn{6}{|c|}{ Phagocytic index } & \multirow{3}{*}{$\begin{array}{c}\text { Over al } \\
\text { mean }\end{array}$} \\
\hline & & \multicolumn{6}{|c|}{ Days post vaccination } & \\
\hline & & $1^{\mathrm{st}}$ & $3 \mathrm{rd}$ & 5 th & 7 th & 10 th & 15 th & \\
\hline Gp (1) vaccinated with Aluminium & & 0.23 & 0.29 & 0.36 & 0.33 & 0.31 & 0.24 & $0.29^{\mathrm{d}}$ \\
\hline $\begin{array}{l}\text { hydroxide gel Inactivated RVF vaccine } \\
\text { (one dose) }\end{array}$ & 5 & $\begin{array}{c} \pm \\
0.08\end{array}$ & $\begin{array}{c} \pm \\
0.09\end{array}$ & $\begin{array}{c} \pm \\
0.11\end{array}$ & $\stackrel{ \pm}{ \pm}$ & $\begin{array}{c} \pm \\
0.07\end{array}$ & $\begin{array}{c} \pm \\
0.11\end{array}$ & $\stackrel{ \pm}{0.08}$ \\
\hline Gp (2) vaccinated with Aluminium & & 0.31 & 0.35 & 0.34 & 0.37 & 0.34 & 0.30 & $0.33^{\mathrm{c}}$ \\
\hline $\begin{array}{l}\text { hydroxide gel Inactivated RVF vaccine } \\
\text { (two doses) }\end{array}$ & 5 & $\begin{array}{c} \pm \\
0.07\end{array}$ & $\begin{array}{c} \pm \\
0.08\end{array}$ & $\begin{array}{c} \pm \\
0.09\end{array}$ & $\begin{array}{c} \pm \\
0.11\end{array}$ & $\begin{array}{c} \pm \\
0.08\end{array}$ & $\begin{array}{c} \pm \\
0.07\end{array}$ & $\begin{array}{c} \pm \\
0.07\end{array}$ \\
\hline Gp (3) vaccinated with Montanide Gel & & 0.45 & 0.56 & 0.66 & 0.81 & 0.74 & 0.65 & $0.64^{\mathrm{b}}$ \\
\hline $\begin{array}{l}\text { 01TM inactivated RVF vaccine 20\% } \\
\text { (one dose) }\end{array}$ & 5 & $\begin{array}{c} \pm \\
0.08\end{array}$ & $\begin{array}{c} \pm \\
0.07\end{array}$ & $\begin{array}{c} \pm \\
0.07\end{array}$ & $\begin{array}{c} \pm \\
0.07\end{array}$ & $\begin{array}{c} \pm \\
0.08\end{array}$ & $\begin{array}{c} \pm \\
0.08\end{array}$ & $\stackrel{ \pm}{ \pm}$ \\
\hline Gp (4) vaccinated with Montanide Gel & & 0.56 & 0.60 & 0.74 & 0.83 & 0.83 & 0.85 & $0.73^{\mathrm{a}}$ \\
\hline $\begin{array}{l}\text { 01TM inactivated RVF vaccine } 20 \% \\
\text { (two doses) }\end{array}$ & 5 & $\begin{array}{c} \pm \\
0.07\end{array}$ & $\begin{array}{c} \pm \\
0.08\end{array}$ & $\begin{array}{c} \pm \\
0.11\end{array}$ & $\begin{array}{c} \pm \\
0.08\end{array}$ & $\begin{array}{c} \pm \\
0.11\end{array}$ & $\begin{array}{c} \pm \\
0.09\end{array}$ & $\begin{array}{c} \pm \\
0.11\end{array}$ \\
\hline $\begin{array}{c}\mathrm{Gp}(5) \\
\text { Non-vaccinated control }\end{array}$ & 5 & $\begin{array}{c}0.13 \\
\pm \\
0.07\end{array}$ & $\begin{array}{c}0.11 \\
\pm \\
0.09\end{array}$ & $\begin{array}{c}0.11 \\
\pm \\
0.08\end{array}$ & $\begin{array}{c}0.11 \\
\pm \\
0.09\end{array}$ & $\begin{array}{c}0.12 \\
\pm \\
0.11\end{array}$ & $\begin{array}{c}0.11 \\
\pm \\
0.07\end{array}$ & $\begin{array}{c}0.11^{\mathrm{e}} \\
\pm \\
0.07\end{array}$ \\
\hline
\end{tabular}

Values with different alphabetic within the right column showed highly significant difference at $\mathrm{P}<0.01$.

\subsection{Detection of interferon $\gamma$ in the blood of mice using Syber green quantitative real-time PCR}

The real-time PCR results revealed that sheep vaccinated with Montanide Gel 01TM inactivated RVF vaccine and boostered 2 weeks apart showed high level of interleukin 6 and 12 as shown in table (9) and (10) and they gradually increased till reach high level in the $7^{\text {th }}$-day post-vaccination, when compared with the level of interleukin 6 and 12 in groups vaccinated with one dose or two doses of Aluminium hydroxide inactivated RVF vaccine. The control results revealed no interleukin 6 and 12 gene expression

Table 9: Detection of interlukin12in blood of sheep using Syber green quantitative real-time PCR:

\begin{tabular}{|c|c|c|c|c|c|c|c|c|}
\hline \multirow{3}{*}{ Sheep group } & \multirow{3}{*}{$\begin{array}{l}\text { No. of } \\
\text { sheep }\end{array}$} & \multicolumn{6}{|c|}{ Cycle threshold of Interleukin 12 gene expression } & \multirow{3}{*}{$\begin{array}{c}\text { Overall } \\
\text { mean }\end{array}$} \\
\hline & & \multicolumn{6}{|c|}{ Days post-vaccination } & \\
\hline & & $1^{\text {st }}$ & $3 \mathrm{rd}$ & 5 th & 7 th & 10 th & 15 th & \\
\hline Gp (1) vaccinated with Aluminium & & 36.430 & 34.932 & 32.010 & 34.000 & 35.910 & 36.250 & $34.922^{\mathrm{a}}$ \\
\hline $\begin{array}{l}\text { hydroxide gel Inactivated RVF vaccine } \\
\text { (one dose) }\end{array}$ & 5 & $\begin{array}{l} \pm \\
0.657\end{array}$ & $\begin{array}{c} \pm \\
0.254\end{array}$ & $\begin{array}{c} \pm \\
0521\end{array}$ & $\stackrel{ \pm}{ \pm}$ & $\begin{array}{c} \pm \\
0.162\end{array}$ & $\begin{array}{c} \pm \\
0.236\end{array}$ & $\begin{array}{c} \pm \\
0.524\end{array}$ \\
\hline Gp (2) vaccinated with Aluminium & & 35.192 & 33.817 & 31.910 & 31.300 & 32.714 & 33.913 & $33.141^{\mathrm{b}}$ \\
\hline $\begin{array}{l}\text { hydroxide gel Inactivated RVF vaccine } \\
\text { (two doses) }\end{array}$ & 5 & $\begin{array}{c} \pm \\
0.296\end{array}$ & $\begin{array}{c} \pm \\
0.056\end{array}$ & $\stackrel{ \pm}{ \pm}$ & $\stackrel{ \pm}{ \pm}$ & $\begin{array}{l} \pm \\
0.435\end{array}$ & $\stackrel{ \pm}{ \pm}$ & $\stackrel{ \pm}{0.566}$ \\
\hline Gp (3) vaccinated with Montanide Gel & & 35.000 & 32.110 & 29.988 & 30.179 & 31.876 & 32.333 & $31.194^{\mathrm{c}}$ \\
\hline $\begin{array}{l}\text { 01TM inactivated RVF vaccine } 20 \% \\
\text { (one dose) }\end{array}$ & 5 & $\begin{array}{l} \pm \\
0.145\end{array}$ & $\stackrel{ \pm}{ \pm}$ & $\stackrel{ \pm}{ \pm}$ & $\begin{array}{l} \pm \\
0.562\end{array}$ & $\stackrel{ \pm}{ \pm}$ & $\begin{array}{c} \pm \\
0.524\end{array}$ & $\begin{array}{l} \pm \\
0.516\end{array}$ \\
\hline Gp (4) vaccinated with Montanide Gel & & 34.349 & 31.919 & 28.791 & 28.001 & 29.899 & 31.189 & $30.691^{\mathrm{d}}$ \\
\hline $\begin{array}{c}01 \mathrm{TM} \text { inactivated RVF vaccine } 20 \% \\
\text { (two doses) }\end{array}$ & 5 & $\begin{array}{c} \pm \\
0.235\end{array}$ & $\begin{array}{c} \pm \\
0.285\end{array}$ & $\begin{array}{c} \pm \\
0342\end{array}$ & $\begin{array}{c} \pm \\
0.268\end{array}$ & $\begin{array}{c} \pm \\
0.666\end{array}$ & $\begin{array}{l} \pm \\
0.522\end{array}$ & $\stackrel{ \pm}{0.666}$ \\
\hline $\begin{array}{c}\text { Gp (5) } \\
\text { Non-vaccinated control }\end{array}$ & 5 & No Cycl & eshold & & & & & \\
\hline
\end{tabular}

Primer dimer (Real-time negative control (mix+H2o+primers): 36.32 .

Values with different alphabetic within the right column showed highly significant difference at $\mathrm{P}<0.01$. 
Evaluation of The Cellular and Humoral Immune Response of Sheep ......

Table 10: Detection of interleukin 6 in the blood of sheep using Syber green quantitative real-time PCR:

\begin{tabular}{|c|c|c|c|c|c|c|c|c|}
\hline \multirow{3}{*}{ Sheep group } & \multirow{3}{*}{$\begin{array}{l}\text { No. of } \\
\text { Sheep }\end{array}$} & \multicolumn{6}{|c|}{ Cycle threshold of Interleukin 6 gene expression } & \multirow{3}{*}{$\begin{array}{c}\text { Overall } \\
\text { mean }\end{array}$} \\
\hline & & \multicolumn{6}{|c|}{ Days post-vaccination } & \\
\hline & & $1^{\text {st }}$ & $3 \mathrm{rd}$ & 5 th & 7 th & 10 th & 15 th & \\
\hline Gp (1) vaccinated with $\mathrm{AlOH}$ gel & & 37.111 & 36.399 & 34.197 & 35.911 & 36.768 & 37.318 & $36.284 a$ \\
\hline $\begin{array}{l}\text { Inactivated RVF vaccine (one } \\
\text { dose) }\end{array}$ & 5 & $\begin{array}{c} \pm \\
0.647 \\
\end{array}$ & $\begin{array}{c} \pm \\
0.666 \\
\end{array}$ & $\begin{array}{c} \pm \\
0.388 \\
\end{array}$ & $\begin{array}{c} \pm \\
0.196 \\
\end{array}$ & $\begin{array}{c} \pm \\
0.250 \\
\end{array}$ & $\begin{array}{c} \pm \\
0.813 \\
\end{array}$ & $\begin{array}{c} \pm \\
0.625 \\
\end{array}$ \\
\hline Gp (2) vaccinated with $\mathrm{AlOH}$ gel & & 36.401 & 35.760 & 33.312 & 32.719 & 34.714 & 33.000 & $34.317 b$ \\
\hline $\begin{array}{l}\text { Inactivated RVF vaccine (two } \\
\text { doses) }\end{array}$ & 5 & $\stackrel{ \pm}{ \pm}$ & $\begin{array}{c} \pm \\
0.035 \\
\end{array}$ & $\begin{array}{c} \pm \\
0.250 \\
\end{array}$ & $\begin{array}{c} \pm \\
0.388 \\
\end{array}$ & $\begin{array}{c} \pm \\
0.289 \\
\end{array}$ & $\begin{array}{c} \pm \\
0.745 \\
\end{array}$ & $\begin{array}{c} \pm \\
0.564 \\
\end{array}$ \\
\hline Gp (3) vaccinated with Montanide & & 36.011 & 34.310 & 31.990 & 31.011 & 33.100 & 32.985 & $33.234 \mathrm{c}$ \\
\hline $\begin{array}{c}\text { Gel } 01 \mathrm{TM} \text { inactivated } \mathrm{RVF} \\
\text { vaccine } 20 \% \text { (one dose) }\end{array}$ & 5 & $\stackrel{ \pm}{ \pm}$ & $\begin{array}{c} \pm \\
0.357\end{array}$ & $\begin{array}{c} \pm \\
0.284\end{array}$ & $\begin{array}{c} \pm \\
0.384\end{array}$ & $\begin{array}{c} \pm \\
0.458\end{array}$ & $\begin{array}{c} \pm \\
0.168\end{array}$ & $\begin{array}{c} \pm \\
0.359 \\
\end{array}$ \\
\hline $\begin{array}{c}\text { Gp (4) vaccinated with Montanide } \\
\text { Gel } 01 \mathrm{TM} \text { inactivated RVF } \\
\text { vaccine } 20 \% \text { (two doses) }\end{array}$ & 5 & $\begin{array}{c}35.313 \\
\pm \\
0.512 \\
\end{array}$ & $\begin{array}{l}33.186 \\
\pm \\
0.215 \\
\end{array}$ & $\begin{array}{l}31.043 \\
\pm \\
0.251 \\
\end{array}$ & $\begin{array}{l}30.703 \\
\pm \\
0.382 \\
\end{array}$ & $\begin{array}{l}31.723 \\
\pm \\
0.142 \\
\end{array}$ & $\begin{array}{c}32.001 \\
\pm \\
0.325 \\
\end{array}$ & $\begin{array}{c}32.328 \mathrm{~d} \\
\pm \\
0.384 \\
\end{array}$ \\
\hline $\begin{array}{c}\text { Gp (5) } \\
\text { Non-vaccinated control }\end{array}$ & 5 & \multicolumn{7}{|c|}{ No cycle threshold } \\
\hline
\end{tabular}

Primer dimer (Real-time negative control (mix+H2o+primers): 35.482

Values with different alphabetic within the right column showed highly Significant difference at $\mathrm{P}<0.01$.

\section{DISCUSSION}

The progress in vaccine production is directed towards the selection of the proper adjuvant that can elaborate high and long-standing immunity. Adjuvants are considered one of the important factors in vaccine formulations as it can influence the immunity and increase the immune response referred to the vaccine. So this study was applied to evaluate the immune response and duration of immunity in sheep vaccinated with $20 \%$ Montanide Gel $01^{\mathrm{TM}}$ inactivated RVF vaccine in comparison to aluminium hydroxide gel inactivated RVF vaccine Toxicity test of Montanide Gel $01^{\mathrm{TM}}$ adjuvant were done by $\mathrm{I} / \mathrm{P}$ inoculation of adult mice, with four concentrations of Montanide Gel $01^{\mathrm{TM}}(10 \%, 15 \%, 20$ and $25 \%)$ which revealed no signs of toxicity during 10 days post-inoculation as shown in table (1).

The results of adsorption test revealed that the most suitable concentration of Montanide Gel $01^{\mathrm{TM}}$ was $20 \%$ as it was the first concentration showed no cytopathic effect of the supernatant after centrifugation when inoculated in tissue culture and no virus detected by titration as shown in table (2). Sterility test showed that the vaccines were free from any bacterial, fungal and mycoplasma contaminations, these results agreed with OIE (2012) that revealed the vaccine batch must be free from bacteria, fungus and mycoplasma. by applying clinical examination on the vaccinated sheep, no abnormal signs were observed, no elevation of body temperature and no postvaccinal reaction at the site of injection.
Evaluating the potency of the prepared vaccines in adult mice as shown in table (3), revealed that the vaccines gave protection in mice with $\mathrm{ED}_{50} / \mathrm{ml}$ $(0.0017$ and $0.0011 / \mathrm{ml})$ for the inactivated $\mathrm{RVF}$ vaccines with aluminium hydroxide gel, Montanide Gel $01^{\mathrm{TM}} 20 \%$ ) respectively. Serum neutralization test revealed that sheep vaccinated with one dose Aluminum hydroxide inactivated RVF vaccine showed that the neutralizing antibodies started to rise from the 1st-week post-vaccination $\left(0.9 \log { }_{10}\right)$ and reached the protective level $(1.7 \log 10)$ on the 2 nd week postvaccination as shown in table (4), and then reached the peak $\left(3 \log _{10}\right)$ at the 2 nd month post-vaccination and continue in protective level till 8th month postvaccination, these results were in agreement with those obtained by El Nimr (1980) and Eman (1995) who recorded that the protective NI level obtained by the inactivated vaccines within 2 weeks post-vaccination, the neutralizing antibody reaches the peak (2.6 logs 10$)$ at the 2 nd month post-vaccination and continue within the protective level till 6th month post-vaccination.

This results agreed with that obtained by Heba, (2013) who found protective antibody level of sheep vaccinated with inactivated RVF vaccine till 7 months post-vaccination while in sheep vaccinated with two doses of aluminium hydroxide gel, the NI level reached the protective level $\left(1.7 \log { }_{10}\right)$ at the $2^{\text {nd }}$-week postvaccination and reached to the peak at $2^{\text {nd }}$-month postvaccination and continue in protective level till the $10^{\text {th }}$-month post-vaccination. 
In sheep vaccinated with one dose and two doses of Montanide Gel $01^{\mathrm{TM}}$ inactivated RVF vaccines (20\%), the neutralizing antibodies started to rise after vaccination to reach its protective level $\left(2.04 \log _{10}\right.$ and $2.07 \log _{10}$ ) respectively on the $1^{\text {st }}$ week postvaccination, and increased gradually to its peak (3.82 $\log 10)$ at the $3^{\text {rd }}$ month post-vaccination in sheep vaccinated with one dose and in sheep vaccinated with two doses reached the peak at $2^{\text {nd }}$ month postvaccination $\left(3.99 \log { }_{10}\right)$ and stay within the protective level $\left(1.7 \log _{10}\right.$ and $\left.1.7 \log _{10}\right)$ respectively at the $\left(11^{\text {th }}\right.$ month and $13^{\text {th }}$-month post-vaccination respectively as shown in table (4).

These results in concordance with those reported by Dupuis et al., (2008) who observed that using of Montanide $\mathrm{Gel} 01^{\mathrm{TM}}$ as adjuvant gave sufficient early immune response in vaccinated cattle and with El Sayed et al., (2011) who found that Montanide Gel $01^{\mathrm{TM}}$ adjuvant vaccine gives an intense immune response and showed prolongation of antibody secretion in comparison to the aluminium hydroxide. Also, our results agreed with Deville et al., (2008); Parker et al., (2009); Deville et al., (2011) and AbulMagd (2014) who reported that antibodies production induced by Montanide Gel $01^{\mathrm{TM}}$ based vaccine was higher than aluminium based vaccines.

Moreover, confirmation of humoral immune response was assessed by ELISA as shown in table (5) as it is considered the sensitive and accurate test to evaluate the immune status of RVF in animals sera (Taha et al., 2002 and Fafetine et al., 2007). When the ELISA test was done on the same serum samples, the results were in parallel course with that obtained by SNT. Similar findings were reported by Eman, (1995) and Mona, (2008).

Results of cell proliferation expressed by optical density were high in sheep vaccinated with one dose of Montanide Gel $01^{\mathrm{TM}}$ inactivated RVF vaccine but more strong in sheep vaccinated with two doses of Montanide $\mathrm{Gel} 01^{\mathrm{TM}}$ inactivated RVF vaccine as shown in table (6). While in sheep vaccinated with one dose of $\mathrm{AL}(\mathrm{OH})_{3}$ gel inactivated $\mathrm{RVF}$ vaccine showed slight elevation of cell proliferation and these results agreed with that obtained by Hammad (2015) who recorded slight elevation in sheep vaccinated by RVF vaccine with Aluminium hydroxide gel.

Results of phagocytic activity expressed by phagocytic percentage and phagocytic index showed early significant in sheep vaccinated with one dose of Montanide Gel $01^{\mathrm{TM}}$ inactivated RVF vaccine as shown in table (8) and (9) but more strong in sheep vaccinated with two doses of Montanide Gel $01^{\mathrm{TM}}$ inactivated RVF vaccine and nearly no significance in sheep vaccinated with one dose of $\mathrm{AL}(\mathrm{OH})_{3}$ gel inactivated RVF vaccine which agreed with Hammad, (2015).

IL 6 and IL 12 play an important role in the generation of cell-mediated immunity (Irene $\boldsymbol{e t}$ al., 1999), So in this study, by using RT-PCR the level of IL6 and IL12 gene expression was detected in sheep vaccinated with different doses of Montanide Gel $01^{\mathrm{TM}}$ inactivated RVF vaccine. The results revealed that two doses of Montanide Gel $01^{\mathrm{TM}}$ inactivated RVF vaccine induced a higher level of IL 6 and IL12 gene expressions than Aluminium hydroxide gel inactivated RVF vaccine as shown in table (10).

\section{CONCLUSION}

From the obtained results, it can be cocluded that, Montanide Gel $01^{\mathrm{TM}}$ was highly immunogenic when used as adjuvant in preparation of RVF vaccine inducing a higher level of antibody titre with prolonged duration of immunity, higher cell proliferation and phagocytic activity and IL6 and IL12 level so allowing a better control of the disease, so we recommend it to be used in animal vaccination to increase the level and duration of immune response.

\section{REFERENCES}

ABDEL-GAFFAR, S.; MOHSEN, A.; AYOUB, N.; ELNIMR, M. AND FATHIA, M. 1979. Rift Valley fever in Egypt III. Diagnosis and vaccination. $14^{\text {th }}$ Arab. Vet. Cong., 24-29 march Cairo, page 1-11.

ABUL-MAGD D.M. 2014. Vaccination against Rift Valley Fever disease. PhD.Thesis, Department of Animal Medicine Faculty of Veterinary Medicine, Benha University,

ARONTHEY AND HAZEN 1988. Role of yeast cell growth temperature on candida Albicans virulence in mice. Immunol, 56; 2884- 2890.

BLACKBURN, N. K. AND BESSELAAR, T. G. 1991. A study of the effect of chemical inactivants on the epitopes of Rift Valley fever virus glycoproteins using monoclonal antibodies. J Virol Methods 33:367-374.

DALSGARRD, K.; HILGERS,L. AND TROUVE,G. 1990. Classical and new approache to adjuvant use in domestic animals. Adv. Vet. Sci.Comp. Med., 35: 121-159.

DEVILLE S, PARKER R. AND LAVAL A. 2008. Adjuvant formulation for infeluenza H1N1 and H3N2 pig vaccines: Montanide ${ }^{\mathrm{TM}}$ Gel safety and Efficacy study.Proceedings of the Conference of Research of Workers in Animal Disease, Chicago.

DEVILLE S, CARNEAUX E, BERTRAND F, CAUCHARD S, CAUCHARD J AND DUPUSISL 2011. Adjuvant formulation for companion animals vaccines. Procedia in Vaccinology (4):104-112.

DIGOUTTE J.P. AND PETERS C.J.1989. General aspects of the 1987 Rift Valley fever epidemic in Mauritania. Res. Virol.; 140:27-30.

DUPUIS, L.; DEVILLE, S.;BETERAND, F. ; LAVAL, A. AND AUCOUTURIER, J. 2008. Adjuvant 
formulation for multivalent pig vaccines: Pasteurella multocida anatoxins and inactivated Bordetella bronchiseptica, Montanide Gel 01TM safety study. proceedings of the international pig veterinary society. Durban. Rift Valley Fever. Adv. Vet. Sci., 10(65): 127.

EBRAHIM, B., ROY, D.J., BIRD, P. AND SANGER, D.R. 1995. Cloning, sequencing and expression of the ovine Interlukin -6 gene. Cytokine, 7: 232-236.

EDUARD, K.1985. Progress in enzyme immunoassays : production of reagents, experimental design and interpretation . Bulletin of the world health organization, 63(4):793-811.

EMAN. M. S. S.1995. Studies on RVF vaccine inactivated with Binary. Ph. D. Sc. Thesis Microbiology, Fac. of Vet. Med., Cairo -Univ.

El NIMR, M.M.1980. Studies on the inactivated vaccine against Rift Valley Fever. Ph. D. Thesis (Microbiology) Fac. Vet. Med. Assuit Univ. Egypt.

EI SAYED ,E.L.;ABDEL-HADY, M.K.; ZAKI, E.S.A.; MAHMOUD, M.S.; AHMED, I.K.. AND GHALY, H.M.2011. Study on improvement of Entero-3 vaccine using montanide ${ }^{\mathrm{TM}}$ gel as an adjuvant. Proceeding of $4^{\text {th }}$ Scientfic Conference of Animal Wealth Research in middle East and north Africa, foreign agriculture relations (FAR), Egypt,551-559.

FAFETINE, J.M.; TIJHAAR, E.; PAWESKA， J.T.; NEVES, L.C.; HENDRIKS, J.; SWANEPOEL, R.; COETZER, J.A.; EGBERINK, H.F. AND RUTTEN, V.P. 2007. Cloning and expression of Rift Valley fever virus nucleocapsid $(\mathrm{N})$ protein and evaluation of a N-protein based indirect ELISA for the detection of specific $\operatorname{IgG}$ and $\operatorname{IgM}$ antibodies in domestic ruminants Vet. Microbiol,; 121 (1-2): 29-38.

HAMMAD, M.Y. 2015. Some studies on Rift Valley Fever vaccine, PhD. Thesis, Faculty of veterinary medicine, Benha University.

HARMON, B G. AND GLISSON, J. R.1989. In vitro microbial activity of avian peritoneal macrophages. Avian Dis., 33: 177-181.

HEBA ABD El-MONEM KHAFAGY 2013. Some studies on living attenuated Rift Valley Fever vaccine.M. Vet. Sic Thesis, (Infectious), Fac. Vet. Med. Benha. Univ.

HUSSEIN, H.A.1989. Immuno suppressive effect of MDV M.V.SC, Thesis, Department of Virology Fac. of Vet. Medicine, Cairo Univ.

IRENE S. LEAL, BRGITTE SMEDEGARD, PETER ANDERSEN, AND RUI APPELBERG 1999. interleukin 6 and interleukin 12 participate in induction of type 1 protective t-cell response during vaccination with a tuberculosis subuinit vaccine. Infect immune; 67 (11): 5747-5754.

KATHRYN, A.; HUBBARD, B. S. C.; ARTHUR BUSKERVILLE, AND JOHN 1991. Ability of a mutagenized virus variant to protect young lambs from Rift Valley Fever. Am. J. Vet. Res., Vol.52: 505.

MACPHERSON, J.A. AND STOCKER,N.G. 1962. Polyoma Transformation of hamester cell clones an investigation of hamester cell clonesof genetic factors affecting all competence. Virology, 16: 147-151.

OIE, 1989. Manual of recommended diagnostic techniques and requirements for biological products of lists $\mathrm{A}$ and $\mathrm{B}$ diseases. Internation. Committee of the OIE Vol. 2 P. 1/8 - 8/8.

OIE 2012. OIE Terrestrial manual 2012, chapter 2.1.14.

OIE, 2014. Rift Valley Fever, chapter 2.1.14.

LEE, L.F. 1984. Proliferative response of chicken B and T lymphocyte to mitogene. Vet.Med, 15:44-52.

LUCY, F .L. 1977. Chicken Lymphocyte stimulation by mitogenes .Amicroassay with whole blood cultures. Avian Dis., 22:296-307.

MONA, F. M. 2008. Experimental studies of Smithburn Attenuated Rift Valley Fever Virus Vaccine in pregnant sheep. Ph. D. Thesis (Virology). Fac. Vet. Med. Benha University, Egypt.

PARKER, R.; DEVLLE, S.; DUPUIS, L.; BERTR, F. AND AUCOUTURIER, J. 2009. Adjuvant formulation for veterinary vaccines: Montanide Gel 01TM safety profile procedia in Vaccinology, 1(1) 140-147.

REED, L. J. AND MUENCH, H. 1938. A SIMPLE METHOD FOR ESTIMATING 50 PERCENT END POINT. AM, J. HYG., 27:493-497.

RICHARDSON AND SMITH, 1981. Resistance of virulent and attenuated strains of Candida albicans to intracellular killing by human and mouse phagocytes.J. Infect. Dis.; 144:557-565.

SANGEETA BUDHIA, LISA F. HARING, IAN MCCONNELL, And BARBARA A. BLACKAWS 2006. quantitation of ovine cytokine mRNA by realtime RT-PCR. Journal of immunological methods 309. 160-172.

SCUDIERO, D. A.; SHOEMAKER,R.H.; PAULL, K.D.;MONKS, A.; TIERNEY, S.; NOFZIGER, T.H.; CURRENS, M. J.; SENIFF, D. AND BOYD, M. R.1988. Evaluationa of soluble tetrazolium / Formazan Assay for cell growth and drug sensitivity in culture using human and other tumer cell lines. Cancer Res., 48:4827-4833.

SLATER, T.F., SAWYER, B. C. AND STRIIULI, U. 1963. Biochim. Biophys.Acta, 77, 383.

SPSS .2007. SPSS Inc. Released 2007. SPSS for Windows, Version 16.0. Chicago, SPSS Inc.

TAHA, M. M.; ELIAN, K.; GIHAN, K.; HASSAN, K. AND FATMA, S. 2002. Standardization of both Rift Valley Fever cell lysate and supernatant antigens used in ELISA comparing with SNT\& AGPT. Vet. Med. J., Giza. Vol. 50, No. 4. 987 - 992.

VOLLER, A.; BIDWELL, D. AND BARTLETT, A. 1976. Microplate enzyme immunoassay for the immunodiagnosis of virus infection. Am. Soc. for Micro., 506-512.

WHO 1983. The use of vet. Vaccines for prevention and control of RVF. Bulletin of the World Health Org., 61(2): 261-8 .

How to cite this article:

Abd El Rahman S.E., Abul Magd, D. M, Atwa, M. H., Soliman, S. M.. 2020. Evaluation Of The Cellular And Humoral Immune Response Of Sheep Vaccinated With Inactivated Rift Valley Fever Vaccine Adjuvanted With Montanide Gel $01^{\mathrm{tm}}$. Journal of Applied Veterinary Sciences, 5(1): 22-34. DOI : https://dx.doi.org/10.21608/javs.2020.21145.1002 